\title{
POR QUÉ LA HISTORIA ESCRITA ESTÁ ABIERTA Y SIEMPRE LO ESTARÁ*
}

\author{
Joaquín Fermandois \\ Pontificia Universidad Católica de Chile \\ UNA HISTORIA DEBATIDA
}

\begin{abstract}
Tienen razón los comentaristas al sostener que el 11 de septiembre de 1973 encenderá para siempre una pregunta sobre el carácter de Chile y de su historia. El bombardeo de La Moneda es lo que más despierta la curiosidad de los visitantes al Museo de la Memoria, inaugurado en enero de 2010. Devino en el símbolo de la crisis de Chile y el preámbulo de unos años extraordinariamente violentos en la historia republicana del país. Por ello, la casi totalidad de los análisis de la época de la Unidad Popular la miran como algo inseparable del régimen militar
\end{abstract}

Joaquín Fermandois Huerta. Profesor de historia contemporánea de la Pontificia Universidad Católica de Chile. Ha escrito Política y trascendencia en Ernst Jünger 1920-1934 (1982); Chile y el mundo 1970-1973. La política exterior del gobierno de la Unidad Popular y el sistema internacional (1985); Abismo y cimiento. Gustavo Ross y las relaciones entre Chile y Estados Unidos 1932-1938 (1997); Mundo y fin de mundo. Chile en la politica mundial. 1900-2004 (2005); La revolución inconclusa. La izquierda chilena y el gobierno de la Unidad Popular (2013). Email: jfermand@uc.cl.

* Las siguientes reflexiones son la respuesta de Joaquín Fermandois a las reseñas sobre su libro La revolución inconclusa (CEP 2013) aparecidas tanto en este número de Estudios Públicos, como en las dos entregas anteriores, a saber: María Teresa Infante, "La revolución inconclusa", Estudios Públicos 133 (2014), 165-183; Sofía Correa Sutil, “Democracia popular en Chile?”, Estudios Públicos 134 (2014), 187-203; y Alan Angell, “Crónica de una tragedia”, Estudios Públicos 135 (2014), 251-268. 
que le siguió, poniendo énfasis en las ejecuciones, desapariciones (que en lo general implicaban tormentos hasta provocar la muerte) y en el uso generalizado de la tortura como medio de interrogación, al menos en los primeros años. También es indudable que el país había saltado a un estrellato mundial con la elección de Salvador Allende en 1970, hasta el punto de que se podría llamar como "utopía lejana" a los años de su gobierno. Lo que vino después fue una suerte de "antiutopía", que, en lo principal, dejaría para siempre marcado al régimen de Pinochet. Este último extraía su legitimación de un rechazo radical del proyecto de la Unidad Popular. Las interpretaciones favorables o que han expresado algún grado de encanto con la "vía chilena" también destacan cierta relación de causa y efecto entre el propósito político que encabezaba Allende y la reacción violenta contra su meta y su dinámica. En este sentido, la dictadura de Pinochet le otorgó a posteriori un aura de legitimidad adicional a la experiencia marxista, que de manera casi inédita se había llevado a cabo en Chile por medios formalmente institucionales ${ }^{1}$.

Todas estas experiencias son también inseparables del advenimiento de la larga transición en Chile en la década de 1980 y el surgimiento de la nueva democracia, celebrada esta última sobre todo en el extranjero muchas veces como "modelo chileno", en un sentido casi siempre laudatorio. Más allá de las exageraciones, como de las críticas acerbas que surgieron de tanto en tanto, el Chile contemporáneo está ligado a este escenario con múltiples miradas, incluyendo a uno que no sabe si está ilusionado o desilusionado con el país en los momentos en que se escriben estas líneas. Esto nos lleva al viejo tema de la historiografía acerca de las continuidades y discontinuidades de los procesos históricos concretos, como siempre un dilema insoluble si lo queremos explicar al modo de un fenómeno de la naturaleza. El lenguaje de la historia posee siempre un alcance en algunos grados metafórico; son los granos de sal imprescindibles, aunque resbaladizos, cuando queremos explicar conductas humanas que tienen que ver con lo que hacemos y hemos hecho.

${ }^{1}$ Esta relación la he explicado en varias publicaciones previas. En especial, debo señalar Mundo y fin de mundo. Chile en la política mundial 1900-2004 (Santiago: Ediciones Universidad Católica de Chile, 2005). Es válido para La revolución inconclusa lo que había afirmado en aquel libro: “(Para) el historiador contemporáneo, que ha vivido una parte del tiempo del que trata la obra, ese tiempo 'le es presente'. Por lo tanto, asumo que yo también soy fuente, por lo vivido, lo percibido, lo temido, lo ansiado, lo gozado" (18). 
Precisamente el Chile que va entre 1970 hasta nuestros días ha sido una combinación de continuidades en la evolución y de rupturas, aunque a veces tienden a confundirse. Es indudable que el Golpe de Estado de 1973 se acerca más al modelo de la ruptura, mientras que la transición (corta) a la democracia entre 1988 y 1990 expresa una evolución que parece rescatar una continuidad. La misma década de 1980 se nos aparece como una extraña y a veces inquietante combinación de abismos sin regreso y de transformaciones positivas que pocos años antes nos hubieran aparecido como un deseo reprimido. Al final, en consonancia y en vanguardia con cambios globales que normalmente son considerados como el fin de la Guerra Fría - aunque para este caso los prefiero denominar como la maduración y convergencia chilena con el modelo occidental que transformó al final al mismo régimen militar-, se abrió paso a una nueva época que no pretendía romper del todo con las dos décadas anteriores. Mirados en su conjunto, estos 44 años los vemos como una historia fascinante que a la vez nos puede producir exasperación, tedio y frustración. Estoy seguro, sin embargo, de que para quienes tengan presente el desarrollo global en este casi medio siglo, y aun teniendo en cuenta los extensos hoyos negros de la cultura contemporánea, la mayor parte de los observadores la mirarían con prudente optimismo.

En correspondencia con sus tensiones internas, la crisis nacional del año final de la Unidad Popular, la crisis que representó la dictadura de Pinochet y los años de la nueva democracia deben estar a la vista al momento de pensar la historia de Chile. Esto vale también para introducirnos en el amplio marco del pasado a fin de entender el presente. Por ello, La revolución inconclusa está precedida de un capítulo dedicado a pensar el tema del orden y de la democracia en la historia de Chile. Su objetivo es tanto recordar la fragilidad de nuestras instituciones como subrayar su relativa fortaleza y arraigo en comparación con las repúblicas latinoamericanas, aunque no exista una diferencia que pudiéramos calificar de esencial. Me parecía por lo mismo que, como a lo largo de todo el libro, mi interpretación de los hechos no podía estar separada de la experiencia de la política moderna, cuya ausencia como marco de inteligibilidad muchas veces constituye una carencia no sólo de la historiografía chilena sino también de la latinoamericana. Para evitar esta insuficiencia, hay que referirse a un marco global que consi- 
dere el desarrollo del orden político en el contexto de la modernidad y del mundo en general. No es por casualidad que el siglo XX de China - un Estado y una civilización que han sido de los más (relativamente) aislados - no se pueda comprender sin la referencia de factores tales como nacionalismo y comunismo, incluso hasta el momento presente. Somos muy diferentes y parecidos a la vez, extraños y simultáneos, lo que por lo demás es una de las bases de la existencia histórica, ya que las sociedades humanas poseen analogías y al mismo tiempo una personalidad indiscutiblemente propia e intransferible. La conciencia de esta doble condición es la que a mi juicio debe presidir el lenguaje del historiador al momento de solidificarse un relato.

\section{LO TEÓRICO EN LA HISTORIA DE LA UNIDAD POPULAR}

La misma idea es la que me demandaba explicar la historia de Chile teniendo como actor privilegiado, si bien no único, a la izquierda chilena, desde su remoto origen hasta los albores de la Unidad Popular. Por cierto, existe una abundante bibliografía al respecto que era imposible cotejar en su totalidad, aunque creo haber sido justo al efectuar una selección representativa. No se trata ni de un resumen, ni de un texto pedagógico, sino que surge de la creencia con arreglo a la cual cada historiador escribe la historia de una manera única y personal. Es la base que hace del desarrollo historiográfico moderno un debate constante que termina siendo una suerte de permanente comentario acerca de la condición histórica de la existencia humana. En principio, esto no tendrá fin. Es lo que me llevó a apuntar algunos temas del desarrollo de la izquierda - también de otros actores y de situaciones que no pueden reducirse a la pura oposición de derecha e izquierda - de una manera que me permitía añadir algunos matices, me parece que significativos, que estaban ausentes en otros relatos. Así, por ejemplo, extraje varios textos de la tradición de la izquierda del eximio libro de Sergio Grez, si bien añadiendo mi propia interpretación, fórmula en la cual no lleva ninguna responsabilidad este historiador ${ }^{2}$. Uno podrá diferir a veces de una manera muy marcada de la lectura de otros autores; ello no quita que la

${ }^{2}$ Sergio Grez, De la "regeneración del pueblo" a la huelga general. Génesis $y$ evolución histórica del movimiento popular en Chile (Santiago: RIL Editores, 2007). 
obra propia no podría construirse sin el largo camino intelectual que lo precedió. He tenido siempre una actitud casi instintiva de rechazar esa propensión tan propia a las pequeñas querellas académicas, incomprensibles para otro público, y que en Chile se expresan como el "ninguneo" y el "chaqueteo". Sencillamente, considero que aunque uno puede y debe apreciar positiva o negativamente tal o cual aporte no es dable negarse a justipreciar esa labor que le ha precedido. Ello sencillamente por una razón que es casi práctica. Condenar al olvido y al silencio a otras voces es totalmente contraproducente para el empeño cognitivo que supone nuestra labor de historiador.

Todo autor que se ha sumergido por estudio o por observación vital en un tema específico durante largo tiempo, por décadas como es en mi caso, tendrá algo que añadir al cuadro realizado por otros historiadores o estudiosos del período, entendiendo que el conocimiento histórico no es monopolio de los historiadores. Los intentos que han existido por crear un lenguaje fijo y homogéneo, ya sea por el dogmatismo y el anquilosamiento de algunas escuelas, o por un discurso oficial como los del Estado totalitario, han resultado en un sonoro fracaso, produciendo textos carentes de alma y de vida. La historia escrita, sea de raíz académica, disciplinaria o surgida de los amantes y aficionados a escribirla, será siempre un relato y una interpretación -idealmente, las dos cosas a la vez-, insustituible en cuanto obra personal. La rigurosidad y la ciencia misma aparecen cuando el historiador da cuenta de por qué escoge tal o cuál estrategia, tal o cual nomenclatura y sin ignorar otras preguntas insiste con las suyas. También cuando tiene la suficiente humildad para no subestimar obra alguna del pensamiento. Existe un arbitrio al escoger el lenguaje de la historia, pero la selección del tipo de relato no es arbitraria.

No lo es tampoco el identificar un fenómeno, aunque delimitarlo en estricta temporalidad, es decir, en sus fechas, estará siempre sujeto a discusión y a modalidades un tanto diferentes. Eso vale para la decisión de establecer una relación entre la evolución lenta de los procesos y las rupturas que se le sobreponen. Entre la continuidad y la discontinuidad de la historia aparecen momentos que se presentan a sí mismos como una totalidad, sin que tomemos tampoco muy en serio esta palabra. Efectuamos un corte porque existe un fenómeno a ser destacado. En este caso, el hecho histórico es uno que fue también escogido por la experiencia de los chilenos y del mundo, la Unidad Popular como gobierno 
y como propósito político. Ésa fue la intención que me propuse como autor para intentar contribuir a pensar nuestra historia con motivo del cuadragésimo aniversario del Golpe de Estado de 1973. En otras partes he dado cuenta de mi visión de los hechos acaecidos durante el régimen militar y en la nueva democracia, en particular en Mundo y fin de mundo ${ }^{3}$, así como en varios artículos divulgados por la revista Estudios Públicos. En La revolución inconclusa mi propósito era presentar una historia de la Unidad Popular. ¿Por qué, más allá de las razones externas obvias como el aniversario o su recuerdo constante? El interés del historiador posee una causa, en parte enigmática, que normalmente traducimos al lenguaje como un gusto que no debemos explicar mayormente.

De todas maneras, la historia política y la historia de las ideas e ideologías políticas en el siglo XX ha sido para mí una fuente de interés constante y lo he traducido en varios libros y muchos artículos y ensayos. Después de haber escrito una investigación sobre la política exterior del gobierno de la Unidad Popular, quizás era hora de explicarla como fenómeno político, poniendo el acento — sin olvidar la importante dimensión internacional - en el proceso chileno mismo, porque a toda sociedad humana le es inherente tanto la dimensión interna (nacional en nuestra era) como internacional. Y es cuestionable que sea fecundo el análisis histórico si sólo se realiza desde la perspectiva de lo que sucedió después, algo que los actores no podían prever entonces, tal como nadie lo hará jamás, ya que la predictibilidad no existe, salvo naturalmente que creamos en un absoluto determinismo histórico, marxista o de otra laya, y que por lo tanto también creamos que todo lo que sucede se explicaría completamente por alguna fase anterior. En ese caso no podríamos explicar por qué estamos ahora discerniendo sobre estos asuntos; bastaría con leer a partir de las presuntas leyes de la historia y la sociedad.

Sofía Correa sólo halla dicotomías, arbitrariedades y dislates en el libro. Tiene derecho a sostener sus ideas, ya que el debate y el conocimiento no se sostienen sin estas referencias, por antojadizas que a veces nos puedan parecer. Casi todos los ejemplos concretos que discurre no se convalidan apenas se lee el texto en el contexto, como, por ejemplo, cuando sostiene que algunas afirmaciones no están debidamente referidas a una fuente. Lo están en prácticamente todos los casos, en la frase

\footnotetext{
${ }^{3}$ Ver nota 1 .
} 
anterior o posterior; en el párrafo anterior o posterior. Existen algunos pocos casos, que hacen breve parte del tomo, con los cuales, y en un par de páginas, me adentro en alguna especulación personal, ya que la historia escrita no puede consistir sólo en la reproducción de fuentes; en esa eventualidad, la misma noción de fuente dejaría de tener sentido y el historiador se transformaría en un tipógrafo (dicho con todo respeto a una profesión que fue fundamental en el desarrollo de la izquierda chilena en torno a 1900). De todos modos, estas exploraciones muy personales constituyen para mí el elixir del ser historiador y jamás renunciaría a ellas. El estudio de la historia es sobre todo un momento de leer, meditar, preguntar e intentar algunas respuestas en una tarea inacabable mientras exista historia humana, es decir, mientras existan los seres humanos.

De la misma manera, no he podido hallar en mi libro la afirmación de que Chile era un país principalmente agrario en 1970. Debe haber aquí una confusión, y entiendo que un libro demasiado largo puede cansar al lector o lectora. Lo que sostuve es que Chile, como la inmensa mayoría de las sociedades humanas, tenía una raíz fundamentalmente agraria, un origen principalmente agrario, y eso necesariamente jugaría un papel en su fantasía por todo el resto de su historia. El propósito de la reforma agraria surgió, en gran medida, de esta emoción.

Sofía Correa apuntaba también a que no hago uso de su tesis sobre la derecha en $\mathrm{Chile}^{4}$, a pesar de que me refiero a su libro en la nota respectiva. Sucede que, como señala David Gallagher ${ }^{5}$, su obra sólo comienza realmente a fines de 1938, y en esa parte específica yo estaba hablando de la década de 1930. La nomenclatura de izquierda-derecha, que a mí me parece esencial para comprender la política moderna como sistema de orientación, aunque no necesariamente de todo su contenido, la había tratado yo en una reflexión muy anterior al libro de Sofía, y además la había aplicado a un libro que escribí sobre el Chile político de los años 30 del siglo $\mathrm{XX}^{6}$, también publicado antes que el de la

${ }^{4}$ Sofía Correa, Con las riendas del poder: la derecha chilena en el siglo XX (Santiago: Sudamericana, 2005).

${ }^{5}$ David Gallagher, "Sofía Correa. Con las riendas del poder: la derecha chilena en el siglo XX”, en Estudios Públicos 98 (2005): 304.

${ }^{6}$ Joaquín Fermandois, Abismo y cimiento. Gustavo Ross y las relaciones entre Chile y Estados Unidos, 1932-1938 (Santiago: Ediciones Universidad Católica de Chile, 1997). 
historiadora. Por último, ella echa de menos una mayor referencia a interpretaciones generales de la historia de Chile y a diversas posturas teóricas. No comparto esta aseveración porque, como señalé, jamás he practicado la política de ignorar a otros historiadores, intelectuales o ensayistas. Las preguntas y las respuestas tentativas que desarrollo en el libro hubieran sido imposibles de plantear sin las propuestas de ellos, aunque cualquiera podrá entender que dada la marea de publicaciones que ha provocado este hecho - lo que es observado en el mismo prólogo del libro - no podía citar ni referir a la totalidad del material que se puede hallar. Sólo una enciclopedia lo podría hacer. Lo mismo, tuve que renunciar, con una sola excepción, a incorporar la bibliografía aparecida en el año 2013.

Sin embargo, quiero añadir algo porque sospecho que no es una observación que sólo Sofía me pudiera efectuar. De esta forma, está tácitamente presente en las apreciaciones de Alan Angell y también en las de María Teresa Infante, por la importancia que ella le otorga, al armar su texto, a una amplia gama de estudios sobre el tema. Por ello quisiera señalar lo siguiente. Existen en efecto algunas interpretaciones sobre el Chile moderno que uno no puede soslayar, y que están plenamente referidas en La revolución inconclusa. Entre ellas, siempre sobresalen las de Mario Góngora, Arturo Valenzuela o Tomás Moulian ${ }^{7}$. Las preguntas e hipótesis que ellos formularon están presentes en mis planteamientos. Existe, sin embargo, una vasta serie de autores que, pese a aportar con investigaciones concretas, en algunas ideas esgrimen también la pretensión de representar una "crítica", un "marco teórico", una "perspectiva epistemológica" o una interpretación que debería pasar a ser canónica. Para quienes hemos pasado la vida en esta ocupación, se nos aparecen, en ocasiones, como gestos no faltos de histrionismo para demarcar territorio, cuando no en algunos casos como portadores de las gesticula-

${ }^{7}$ Sobre la importancia que tienen las ideas de Mario Góngora, creo que en mi obra he dado suficiente testimonio, incluyendo La revolución inconclusa. Además lo he citado como fuente de inspiración dos veces en el prólogo. En fin, cada uno ve lo que quiere ver. Sobre Arturo Valenzuela, reseñé su libro - junto a Pamela Constable - Chile under Pinochet: A Nation of Enemies (N. Y., Londres: W. W. Norton \& Co., 1991) en Estudios Públicos 46 (1992). Sobre Tomás Moulian, escribí en las páginas de esta revista un largo artículo, lo más completo que se haya escrito sobre él en Chile y, quizás, en el mundo: Joaquín Fermandois, "Verdad y mito del Chile actual”, Estudios Públicos 69 (1998). 
ciones del clown a los debates de ideas con que, por ejemplo, la genialidad de un Oscar Wilde se encoge hasta quedar de ella sólo la petulancia de cáscara vacía. Sin ir más lejos, está la moda, dentro del mundo de la cultura y de los medios, de autocalificarse de "críticos"; cuando lo hace una masa considerable de intelectuales y académicos quiere decir que se trata de una actitud acrítica. La noción de crítica es harto más polivalente y profunda que lo que sugiere su uso mercantil.

En muchas de estas críticas, que se escudan en la falta de teoría del autor comentado o que se presentan articuladas en un lenguaje que se parece a lo teórico - la pedantería académica, que rara vez alcanza la dignidad del theoros - , se adivina una imitación servil, supongo que muchas veces inconsciente, de las ciencias naturales o exactas, a veces denominadas "duras", lo que resalta su faz inanimada. Creer que una escritura de la historia es mejor o superior porque respondería mecánicamente a la noción de "progreso científico" es una de las grandes ingenuidades de nuestro mundo académico. Puede llegar a ser una tragedia para el pensamiento que se cultiva al alero de la vida universitaria y de la academia en general.

\section{RAIIZ DE LA VIOLENCIA Y LA POLÍTICA MUNDIAL: MÍMESIS}

Dicho esto, es probable, como han señalado los comentaristas, que me haya debido detener un poco más — no mucho, ya que el libro es también largo - en apuntar tentativamente hacia qué factores y actitudes presagiaban una violencia desmesurada después del Golpe. Es atendible la pregunta de si hubo acaso un proceso de adiestramiento para construir una mentalidad de exterminio. Sucede que las respuestas que se han dado hasta ahora no me parecen convincentes como explicaciones madre de la violencia en Chile, especialmente aquella que va desde el Golpe hasta fines de 1973 — cuando murió la mayoría de las víctimas - o la que siguió hasta comienzos de 1977, en los años de la Dina. Lo que emergió de ambas realidades en su conjunto - más que la persecución a extremistas, es decir, a miembros de un aparato armado (sólo una parte del MIR y unos pocos socialistas calificaban como tales días después del 11) - fue el exterminio físico; primero más o menos aleatorio - auténtico terrorismo de Estado- y después el exterminio de cúpulas políticas. Esto es lo que traduce la gravedad de la transgresión 
moral durante el régimen de Pinochet y que, además, no tenía precedentes comparables en la historia de Chile. La violencia posterior, aun aquella horripilante en algunas situaciones (como la del caso degollados en 1985), no se ejecutaba en el marco de un Estado de Derecho, aunque en su gran mayoría al menos se relacionaba con el combate a grupos armados que además ejercían terrorismo. Algo por cierto distinto era la respuesta muy violenta a las "protestas", con demasiados muertos; aunque ése era también el objetivo de una parte de sus convocantes.

Rastreando las posibles raíces de la violencia antes del Golpe - que es lo que quizás debí haber destacado más-, se impone la pregunta de qué la ocasionó. La violencia comenzó el mismo día 11 con ejecuciones más o menos al azar, como si el primer intercambio de disparos de esa mañana hubiera abierto un espacio de guerra total, de cambalache completo de las normas, algo que siempre sucede cuando se está o se cree estar en condición de guerra. La explicación de la influencia francesa - el empleo sistemático de la tortura con resultado de muerte en la Guerra de Argelia - me parece demasiado tenue como influencia directa. Salvo en el tratamiento del cuerpo, tampoco difería de la que habían ejercido los sistemas marxistas a lo largo del siglo XX. Las técnicas de interrogatorio enseñadas en la Escuela de las Américas, en Panamá, centro de estudio y práctica de la contrainsurgencia, hasta donde sabemos no incluían los tipos de persecución y tortura que practicó la Dina. En general, no diferían esencialmente de aquellas a que se someten las tropas especiales para aprender a resistir interrogatorios, que se emparentan, por ejemplo, con aquellos interrogatorios practicados recientemente por la CIA, como el waterboarding, en la llamada guerra al terrorismo.

Por lo demás, el combate entre las fuerzas regulares y las irregulares (urbanas o rurales), a lo largo de la historia, ha desesperado o liberado a las primeras del constreñimiento de la noción de límite y encendido la imaginación en pos del exterminio. Es también lo que efectuaron las fuerzas castristas en Sierra Escambray en 1961 y 1962. De manera circunscrita lo ejercieron las fuerzas de contrainsurgencia en Bolivia, en Uruguay y en Brasil poco antes o en la misma época de la Unidad Popular y la del régimen de Pinochet. El régimen militar peruano de Juan Velasco Alvarado, muy respetado por la izquierda chilena y por Salvador Allende, no tenía nada de democrático y hostigó sistemáticamente a todo opositor real o potencial, aunque no ejerció este tipo de violencia 
extrema. En Argentina, en cambio, tuvo un carácter más exterminador que sobrepasaba al caso chileno, aunque también se originó en el desafío de una guerrilla urbana que centuplicaba a la que podría haber habido en Chile en 1973. Torturas horrorosas nunca dejaron de practicarse en los siglos XIX y XX por algunas tiranías del Caribe, en Asia oriental y, a veces, en las revueltas coloniales antes y después de 1900. Ciertamente, no fue lo que había sucedido en Chile.

Más que la influencia directa del entrenamiento ofrecido por el Pentágono, pienso que resulta más poderoso el factor mimético en el desarrollo de los acontecimientos en nuestro país. El ardor ideológico, el ambiente de confrontación interna, el temor evocado o fingido aunque pudiera transformarse en una emoción real, y que a veces otorgaba licencia autoconferida para desencadenar cualquier extremo-y la lectura, más intuitiva que analítica, de conflictos a lo ancho del mapamundi es lo que más probablemente llevó a los altos grados de violencia a partir del Golpe. Por cierto, ésta es una respuesta tentativa, una hipótesis, aunque me parece que nadie ha propuesto una explicación más rigurosa sobre la urdimbre chilena.

Distingo del problema de la violencia, en cambio, la apreciación de la postura que adquirieron los oficiales de las fuerzas armadas el año 1973. La nomenclatura, corrientemente empleada, de "constitucionalistas" versus "golpistas", aparte de caricaturesca y producida al calor de la batalla desde un solo bando, me parece que simplemente carece de valor epistemológico para comprender en su totalidad la politización de los uniformados, además lo considero francamente infantil. Pienso que el conflicto central de Chile - la polarización que tocó a una gran mayoría de la población - terminó por penetrar también al interior de las fuerzas armadas. En segundo lugar, se dio una tendencia en la política mundial del siglo XX — de alguna manera ya presente en el XIX — respecto de que los ejércitos, puestos ante una disyuntiva radical, jamás eligieran sumarse a una revolución marxista, entre otras razones porque su propia identidad se iba a ver sustancialmente alterada. Como en lo humano no funcionan las leyes a las que se refieren las ciencias naturales, una tendencia general está siempre poblada de excepciones. En este caso, existe una sola: la revolución marxista emprendida por la cúpula militar de Etiopía en 1974, cuyo triste fin ya todos conocemos. 
En éste como en otros casos, mi apuesta historiográfica difiere de otras perspectivas presentes en el ambiente intelectual de nuestro medio, en el sentido según el cual le doy un gran peso a la mímesis - entre espontánea y organizada - que se plasma en la sociedad humana en su totalidad, y que la modernidad ha reforzado al unificar, en términos relativos, las comunicaciones las emociones y hasta un cierto punto las estructuras de convivencia. En cada una de las sociedades y en cada uno de los espacios humanos, la atiborrada diversidad de factores se constituye con rasgos propios y en una síntesis irreemplazable. A la vez, podemos leer en cada una de ellas una parábola general de lo humano. Por ello, la historia de cada una de estas sociedades, y de cada uno de sus momentos, no puede ser apreciada sin el panorama más amplio de la experiencia humana. EP 